\title{
Toxicity effects of Ciprofloxacin on biochemical parameters, histological characteristics, and behaviors of Corbicula fluminea in different substrates
}

\section{Xiaoyu Guo}

Guangdong University of Technology Institute of Environmental and Ecological Engineering

Chenghong Feng ( $201431180041 @$ mail.bnu.edu.cn )

Beijing Normal University School of Environment

\section{Zhe Bi}

National institue of metrology

\section{Akhtar Islam}

Beijing Normal university school of environment

\section{Yanpeng Cai}

Guangdong University of Technology Institute of Environmental and Ecological Engineering

\section{Research Article}

Keywords: Ciprofloxacin, Corbicula fluminea, sediment, oxidative stress, histological alterations, behavioral responses

Posted Date: March 29th, 2021

DOI: https://doi.org/10.21203/rs.3.rs-322835/v1

License: (c) (1) This work is licensed under a Creative Commons Attribution 4.0 International License. Read Full License

Version of Record: A version of this preprint was published at Environmental Science and Pollution Research on November 23rd, 2021. See the published version at https://doi.org/10.1007/s11356-02117509-z. 


\section{Abstract}

Antibiotic toxicity and antibiotic resistance have become significant challenges to human health. However, the potential ecotoxicity of sediment-associated antibiotics remains unknown. In this study, the biochemical responses, histological changes, and behavioral responses of Corbicula fluminea ( $C$. fluminea) exposed to sediment-associated ciprofloxacin (CIP) were systemically investigated. Special attention was paid to the influence of different substrate types. Biochemical analyses revealed that the balance of the antioxidant system was disrupted, eventually leading to oxidative damage to the gills and digestive gland with increasing CIP concentration. Severe histopathological changes appeared along with the oxidative damage. An enlargement of the tubule lumen and thinning of the epithelium in the digestive gland were observed under exposure to high CIP concentrations ( 0.5 and $2.5 \mu \mathrm{g} / \mathrm{g} \mathrm{CIP}$ ). In a behavioral assay, the siphoning of $C$. fluminea in the high concentration exposure groups was clearly inhibited. Moreover, from the integrated biomarker response (IBR) index, the toxicity response gradients of the digestive gland (no substrate-NOS $>$ Sand $>$ Sand and kaolinite clay - SKC $>$ Sand, kaolinite clay, and organic matter-SCO) and gills (NOS $>\mathrm{SCO}>\mathrm{SKC}>$ Sand) were different among substrate exposure groups. The most serious histopathological damage and highest siphoning inhibition were observed in the NOS group. The changes in the morphological structure of digestive gland cells in $C$. fluminea were similar in the other three substrate groups. The inhibition of the filtration rate in the higher concentration groups decreased in the order Sand $>$ SKC $>$ SCO.

\section{Introduction}

Sediments not only serve as a habitat for many aquatic organisms (e.g., benthic invertebrates) but also are a major sink of contaminants in aquatic systems (Ho et al., 2002; Allen Burton, 2002). Extensive research has demonstrated the occurrence and distribution of heavy metals (Feng et al., 2014; Feng et al., 2017), organic pollutants, polar pesticides (Herrero et al., 2018; Rusina et al., 2019), emerging contaminants (microplastics, pharmaceuticals, and steroids) (Yang et al., 2010; Xu et al., 2014; Matić Bujagić et al., 2019), plastic-derived contaminants (Lubecki and Kowalewska, 2019), and various organic micro-pollutants (Qi et al., 2014) in surface sediments. The contaminated sediments pose a threat to aquatic organisms and even to human beings. However, due to the complexity of sediment composition, there are still limited reports on the toxicity of sediment-associated pollutants (Guo and Feng, 2018). This has resulted in a lack of standard sediment pollution controls.

Fluoroquinolone antibiotics (FQs) are heavily used worldwide and are frequently detected in the environment (Wang et al., 2020). Ciprofloxacin (CIP) is one of the most commonly used fluoroquinolone antibiotics (Huang et al., 2020). Due to the existence of ionizable chemical functional groups, CIP is susceptible to adsorption in sediments through cation bridging (Luo et al., 2011; Riaz et al., 2018). It has been reported that concentrations of CIP in sediment reached up to $2118.9 \mathrm{ng} / \mathrm{g}$ in China (Jiang et al., 2014). Due to the wide distribution and the pseudo-durability of CIP in sediments, the potential risk of this kind of pharmaceutical to the benthos is cause for serious concern (Fu et al., 2017). However, the potential aquatic eco-toxicity and human toxicity of CIP via sediment exposure routes remain unidentified 
(Carvalho and Santos, 2016). The eco-toxicity of CIP in sedimentary environments thus needs to be further explored.

As an important medium for the continual buildup and loading of CIP, sediments provide a direct source of exposure for benthos organisms (Chen and Zhou, 2014). Across invertebrate species, bivalves are important sedentary organisms and are often used as the bio-indicators for multiple environmental toxins (Boening, 1999). As a typical freshwater benthic bivalve, Corbicula fluminea (C. fluminea) is dispersed extensively throughout water-sediment boundaries worldwide (Li et al., 2018). The species is a sedimentary filter feeding clam with a very high capacity to bio-accumulate the pollutants dissolved in water (Doherty, 1990; Santos and Martinez, 2014) or bound to suspended particles (Fournier et al., 2005). Such advantages allow the use of $C$. fluminea as a bioindicator of organic contaminants (Wang et al., 2018), metals (Saidani et al., 2019) and some other emerging contaminants (Guilhermino et al., 2018). However, as summarized in our previous research (Guo and Feng, 2018), the investigation of $C$. fluminea's response to organic contaminants has focused on organic pesticides (e.g., chlorpyrifos and diazinon), POPs (e.g., polycyclic aromatic hydrocarbons (PAHs) and polychlorinated biphenyls (PCBs)). As a kind of widely used pharmaceutical, the toxicity of CIP to $C$. fluminea is potentially important, but data on this topic are scarce.

Moreover, based on our previous review, most research investigating the toxicity of pollutants to $C$. fluminea was conducted in the aqueous phase. Only a few previous studies have investigated the effects of sediment-associated pollutants (i.e., the metals and POPs) to C. fluminea (Guo and Feng, 2018). Meanwhile, research concerning sediment-associated toxins has mostly focused on the accumulated content of pollutants in the soft tissues of the $C$. fluminea. However, the actual pollution status is more likely to be reflected by whole-sediment exposure assessments. Studies related to the sedimentassociated antibiotic risk to benthic bivalves are urgently needed. In addition, numerous studies have suggested that different sediment characteristics will influence the transfer of contaminants between the overlying water and sediment phases, thereby altering the bioavailability of the contaminants (Crawford and Liber, 2015). However, only very few studies have investigated the effect of sediment composition on the bioavailability of metals (cadmium and copper) to the benthos in whole sediment (Graney et al., 1984; Roman et al., 2007; Crawford and Liber, 2015). To our knowledge, the potential mechanisms of antibiotic toxicity to benthic bivalves in different substrates (e.g., using multi- parameter estimation of CIP toxicity) have not yet been explored.

Therefore, in this study, a common antibiotic (ciprofloxacin (CIP)) with high binding capacity for sediment was selected as the test pharmaceutical, and $C$. fluminea was selected as the test organism. The main objectives were to explore the oxidative stress, histological changes, and behavioral response following the exposure to sediment-associated antibiotics and to explore the influence of diverse substrate composition on the toxicity of antibiotics to the freshwater bivalve $C$. fluminea.

\section{Material And Methods}




\subsection{Chemicals}

The commonly used antibiotic ciprofloxacin (CIP) was acquired from CNW (Technologies GmbH, Germany). The stock solution of CIP was prepared in Milli-Q® water and stored in brown bottles, then placed in a refrigerator at $4^{\circ} \mathrm{C}$. It should be noted that CIP was selected as ciprofloxacin hydrochloride monohydrate, as this compound can easily dissolve in water. The neutral red indicator, formalin solution, and anhydrous ethanol were of analytical grade.

\subsection{Sediment preparation and spiking}

In the current work, the formulated sediment was prepared using quartz sand $(0.05 \mathrm{~mm}-0.2 \mathrm{~mm})$, kaolinite clay $(<0.002 \mathrm{~mm}$ ) and organic matter (sphagnum moss peat). All of the components of the formulated sediments were commercially available substrates. The proportions of sediment components were based on OECD protocol 218, "Sediment-water Chironomid toxicity using spiked sediment" (OECD, 2004). Four substrate groups were prepared after proper adjustment of the proportions of components listed in the OECD according to the natural sediment types (by weight): (1) the sand group consisted of $100 \%$ quartz sand; (2) the SKC group consisted of 75\% quartz sand, $25 \%$ kaolinite clay; (3) the SCO group was formulated by $75 \%$ sand, $20 \%$ kaolinite clay and $5 \%$ organic matter (4); and the no substrate (NOS) group was composed of $100 \%$ dechlorinated tap water.

In this study, $1000 \mathrm{~g}$ aliquots of dry sediments were added to 4-L glass containers. For each of the exposure concentrations, $1000 \mathrm{~g}$ of sediment was completely mixed with the corresponding concentrations of CIP. The desired concentration of CIP was diluted by stock solution, and the solution was then mixed for $15 \mathrm{~min}$ with the different substrates in the test container using an automatic mixer. Then, the overlying water was added to obtain a ratio (by volume) of sediment to water of 1:4. The depth of the sediment layer in each vessel was $2-3 \mathrm{~cm}$. After spiking, the sediment plus overlying water systems (testing group and control group) were stored in a constant temperature incubator in the dark to equilibrate for $24 \mathrm{~h}$. The equilibration took place under the same conditions as those used during the exposure period.

\subsection{C. fluminea collection and acclimatization}

Healthy $C$. fluminea $(25.84 \pm 5.21 \mathrm{~mm}$ ) were collected from Chongming Island (Shanghai, China). The $C$. fluminea were acclimatized in a clean aquarium containing bottom sand and aerated circulating filtration tap water at $23 \pm 0.5^{\circ} \mathrm{C}$ for at least two weeks in the laboratory. The $C$. fluminea were fed with Spirulina powder every three days during the acclimatization period.

\subsection{Exposure assays}

The exposure experiments with $C$. fluminea were conducted after two weeks of laboratory acclimatization. The experimental concentrations of CIP $(0.01,0.5,2.5 \mu \mathrm{g} / \mathrm{g})$ were designed based on the actual concentrations in natural water observed in our previous studies and the possible extremes. The control and CIP exposure groups were all performed in triplicate. Fifteen healthy $C$. fluminea individuals 
were added to each test container. The exposure period lasted 10 days. In order to reduce interference with the results, the $C$. fluminea were not fed during the exposure period, and the test substrate and overlying water were replaced on a daily basis. The water temperature was maintained at $23 \pm 1^{\circ} \mathrm{C}$ during the 10 days of exposure. Physical and chemical factors such as $\mathrm{pH}$, dissolved oxygen, and conductivity of the overlying water were measured every day. It should be noted that none of the $C$. fluminea died during the 10 days' exposure. All of the $C$. fluminea specimens were removed from the test container and rinsed with Milli-Q® water at the end of the experiment. Then all the samples were prepared for further analysis.

\subsection{Endpoints}

The endpoints chosen to evaluate the effects of CIP consisted of the post-exposure biochemical parameters alterations, morphological observations (tissue structure analysis of the digestive gland), and behavioral observations (filtration rate). The biochemical parameters were the content of the lipid peroxidation product malondialdehyde (MDA), the activity of antioxidant enzymes, such as superoxide dismutase (SOD), catalase (CAT), glutathione peroxidase (GSH-Px), glutathione reductase (GR), and glutathione S-transferases (GST), and the content of glutathione (GSH).

\subsubsection{Biochemical parameters measurements}

Prior to the biochemical measurements, six $C$. fluminea of each treatment group were rinsed with Milli-Q ${ }^{\circledR}$ water, and the organs (gills and digestive glands) were dissected using clean forceps and a scalpel. The entire dissection was carried out on an ice plate. Afterwards, the soft tissues were homogenized using ultra-sonication in $\mathrm{pH} 7.4,0.1 \mathrm{~mol} / \mathrm{L}$ PBS buffer solution $\left(137 \mathrm{mM} \mathrm{NaCl}, 2.7 \mathrm{mM} \mathrm{KCl}, 10 \mathrm{mM} \mathrm{Na}_{2} \mathrm{HPO}_{4}\right.$, $\left.1.8 \mathrm{mM} \mathrm{KH}_{2} \mathrm{PO}_{4}\right)$ under an ice water bath. Afterwards, the samples were centrifuged $\left(4^{\circ} \mathrm{C}\right)$ at $8000 \times \mathrm{g}$ for 15 minutes, and the supernatant was saved for further analysis.

The biochemical indices employed (content of MDA, the activity of antioxidant enzymes (SOD, CAT, GSH$\mathrm{Px}, \mathrm{GR}$, and GST), and the content of GSH) were measured following the instructions of the respective assay kits (Nanjing Jiancheng Bioengineering Institute, China). The results from biochemical analyses were normalized to sample total protein. A protein assay kit (Coomassie brilliant blue method, Nanjing Jiancheng Bioengineering Institute, China) was used for the analysis of protein content in all of the samples.

\section{5.2 Histological analysis}

The digestive gland samples of $C$. fluminea were processed for morphological observation according to the techniques detailed by Cid et al. (2015). After the experiment, four $C$. fluminea were rinsed with Milli$\mathrm{Q} \circledast$ water and immobilization in $10 \%$ formalin solution for at least $48 \mathrm{~h}$. Briefly, after being immobilized, the samples were cleaned for $24 \mathrm{~h}$ using deionized water and then dehydrated using a graded ethanol series $(70-100 \%)$. After that, the digestive gland was embedded in paraffin for histological sectioning. 
Sections of 5-7 $\mu \mathrm{m}$ were cut using a microtome (Leica ATC- RM2235, Germany) and stained with hematoxylin and eosin (H\&E). An optical microscope (Leica DMi8) was used for performing histological observations.

\subsubsection{Siphoning behavior observations}

The filtration rate was measured by the method described by Coughlan (1969) and modified by Chen et al. (2015), which is based on the reduction of the concentration of neutral red solution due to filtration by C. fluminea. At the end of the exposure experiment, five $C$. fluminea individuals from each experimental and control group were rinsed with Milli-Q® water and placed in beakers with $100 \mathrm{~mL}$ neutral red solution $(1 \mathrm{mg} / \mathrm{L})$ and were allowed to siphon for $2 \mathrm{~h}$. The concentration of neutral red solution was tested by measuring the optical density at $530 \mathrm{~nm}$ using a spectrophotometer before and after the two hours' siphoning. The filtration rate was calculated using the following equation from Chen et al. (2015):

$$
\mathrm{m}=\left[\frac{M}{n t}\right] \log \left(\frac{C_{0}}{C_{t}}\right)
$$

where $\mathrm{M}$ is the volume of the neutral red solution; $\mathrm{n}$ is the number of $C$. fluminea used; $\mathrm{t}$ is the time (hrs); $\mathrm{C}_{0}$ is the dye initial concentration; $\mathrm{C}_{\mathrm{t}}$ is the dye concentration at time $\mathrm{t}$, and $\mathrm{m}$ is the filtration rate (mL/animal/h).

\subsection{Statistical analysis}

Each treatment group was conducted in triplicate and the results are presented as the means \pm standard deviations. To evaluate the differences of each parameter between the different treatment (control, 0.01 , 0.5 , and $2.5 \mu \mathrm{g} / \mathrm{g}$ ) in four substrates treatments groups, Two-way analysis of variance (ANOVA) followed by Tukey's post hoc tests was performed using the Data Processing System Version 13.01 (Zhejiang University, Hangzhou, China). Values of $p<0.05$ were considered significant. All data were tested for homogeneity of variance and normality. To summarize all of the biomarker responses from different concentrations of CIP, the integrated biomarker response indexes were calculated by the integrated biomarker response index version 2 (IBRv2) as described by Beliaeff et al. (2002) and modified by Sanchez et al. (Sanchez et al., 2012). The details concerning the calculation method for the IBR are given in the supplementary information.

\section{Results And Discussion}

\subsection{Biochemical parameters responses to the sediment- associated CIP}

The antioxidant defense system is an important reactive oxygen species (ROS) scavenging system in aerobic organisms, as it prevents the organism from oxidative damage (Su et al., 2016). The antioxidant defense system of $C$. fluminea has been successfully employed in the bioassessment of various 
environmental pollutants (Ren et al., 2013; Chen et al., 2015; Yan et al., 2017). However, research is limited concerning the effect of sediment-associated antibiotics on the antioxidant defense system of $C$.

fluminea. The functions and relationships among the biomarkers and the responses of the biochemical parameters (SOD, CAT, GSH-Px, GR, GST, GSH, and MDA) in the gills and digestive glands of $C$. fluminea after 10 days' CIP exposure are shown in Fig. $1(\mathrm{~A}-\mathrm{N})$. The detailed high-resolution figures about the response of each biomarker in the gills and digestive glands were shown in supplementary information (Fig. s1 and Fig. s2).

As the first barrier to oxidative stress, SOD is the fundamental antioxidant enzyme used to clear excess ROS by transforming the ROS to $\mathrm{H}_{2} \mathrm{O}_{2}$ (Wu et al., 2019). Compared with the control group, a significant increase of SOD activity in the gill and digestive gland was observed with $2.5 \mu \mathrm{g} / \mathrm{g}$ CIP exposure $(\mathrm{p}<0.05$, Fig. 1-C, D) in almost all of the substrate groups. Similar results were reported by other researchers, who found that SOD activity in organisms usually increases under stress conditions (Sajjad. Zare, 2012). The increase of SOD activity shown in Fig. 1-C, D indicates that the sediment-associated CIP exposure promoted the generation of ROS. The production of excess ROS increased the SOD activity to protect tissues and cells from oxidative damage.

Similar to SOD, CAT is essential for organism defense under oxidative stress. As shown in Fig. 1(E, F), the CAT activities in gills and digestive glands of all of the substrate groups were all decreased from the $0.01 \mu \mathrm{g} / \mathrm{g}$ treatments and significantly decreased $(P<0.05)$ in the $2.5 \mu \mathrm{g} / \mathrm{g}$ CIP exposure groups. This is due to the functions of SOD and CAT in antioxidant defense systems being collaborative. SOD catalyzes ROS to produce excessive $\mathrm{H}_{2} \mathrm{O}_{2}$, which increases the consumption of CAT. CAT catalyzes a redox reaction in which dismutation of $\mathrm{H}_{2} \mathrm{O}_{2}$ converts it to $\mathrm{O}_{2}$ and $\mathrm{H}_{2} \mathrm{O}$ (Trchounian et al., 2016). In this study, the decrease of CAT in Fig. 1(E, F) showed that the CAT was unable to eliminate excess $\mathrm{H}_{2} \mathrm{O}_{2}$ in time, leading to the excess $\mathrm{H}_{2} \mathrm{O}_{2}$ exceeding the range of regulation of the organism, ultimately affecting the synthesis of CAT and decreasing its enzymatic activity. In addition, glutathione peroxidase enzymes (GSH-PX) were also involved in the detoxification of $\mathrm{H}_{2} \mathrm{O}_{2}$. The GSH-Px activity in the gills and digestive glands was slightly increased in the $0.01 \mu \mathrm{g} / \mathrm{g}$ CIP exposure group, and it was significantly increased in the $2.5 \mu \mathrm{g} / \mathrm{g}$ CIP exposure group $(P<0.05$, Fig. $1-G, H)$. This also indicate the production of excess ROS in $C$. fluminea after exposure to CIP in different substrates.

GSH plays a significant role in the process of removing $\mathrm{H}_{2} \mathrm{O}_{2}$ and -OH. As shown in Fig. 1, two forms of glutathione exist in the organism: reduced glutathione (GSH) and oxidized glutathione (GSSG). In this study, the GSH content in gill tissue (Fig. 1-I) of $C$. fluminea decreased with the increase of CIP concentration, while the GSH content in the digestive gland increased significantly (Fig. 1-J). At the same time, GSH-P and GR activity in gill tissue and digestive gland were increased by all three of the CIP concentrations (Fig. 1-G, H, K, L). Under the action of GSH-PX, the reduced glutathione (GSH) was constantly being oxidized to a disulfide form (GSSG) that is recycled to GSH by NADPH-dependent glutathione reductase (GR) (Csiszár et al., 2016). The decrease of GSH content in gill tissue shown in Fig. 1-I may be due to the production of excessive ROS in $C$. fluminea cells after the invasion of CIP. Under 
the catalysis of GSH-Px, ROS and $\mathrm{H}_{2} \mathrm{O}_{2}$ are removed, and GSH in gill tissue is converted into GSSG, and thus the content of GSH is decreased. This was confirmed by the increase of GSH-Px activity, as shown in Fig. 1-G, $H$.

The increase of GSH content in the digestive gland (Fig. 1-J) may be due to the earlier invasion of CIP in gill tissue than in the digestive gland. Gills are gas-exchange organs and openly exposed to water pollutants (Arini et al., 2014). Although filtration is the central ingestion route of $C$. fluminea, the intake of granular contaminants into the digestive gland arises primarily through swallowing (Ortmann, 2003). The lack of GSH will lead to the toxicity of CIP cannot be effectively removed, thus aggravating the oxidative damage to the organism. Therefore, when GSH in the gill tissue (Fig. 1-I) was transformed into GSSG under the action of GSH-Px, the GR was activated. As shown in Fig. 1- K, L, the GR activity levels in gill and digestive gland were induced after 0.5 and $2.5 \mu \mathrm{g} / \mathrm{g}$ CIP exposure. At the same time, GSSG was transformed into GSH. As an important cellular antioxidant, GR is responsible for the transformation of glutathione disulfide (GSSG) to the sulfhydryl form GSH (Yan et al., 2017). Thus, although the antioxidant defense system of $C$. fluminea was stimulated by the antibiotics, the GSH content in the digestive gland was increased (Fig. 1-J).

GSTs constitute a family of phase II enzymes that are responsible for the removal and decontamination of peroxide (Sheehan et al., 2001). In the current study, the trend of GST activity in gill and digestive gland of $C$. fluminea was opposite to that of the content of GSH (Fig. 1). In the gills, the GSH content (Fig. 1-I, J) decreased with the increase of CIP concentration, while the activity of GST (Fig. 1-M, N) was induced with the increase of CIP concentration. This may be due to the excessive production of ROS, which promotes the activation of phase II enzymes pathway. GST can conjugate electrophilic compounds with GSH (Fig. 1) and take part in cellular defense against the harmful effects of xenobiotics and oxidative metabolic byproducts (Silva et al., 2009). Thus, the activity of GST in the gills (Fig. 1-M) is promoted to catalyze the combination of GSH and CIP to form a complex (GSX) to be discharged from the body. In the digestive gland, the GSH content increased (Fig. 1-J) with the increase of CIP concentration, while the activity of GST (Fig. 1-N) was decreased with the increase of CIP concentration. The reason might be that the CIP stress conditions led to excessive ROS accumulation, resulting in the decrease of GST in the process of catalytic removal of excessive xenobiotics by GSH.

Enzyme and non-enzyme in the antioxidant defenses can reflect the condition of the free radical scavenging system, while lipid peroxidation (LPO) is often used to reflect the degree of free radical reactions in organisms and to indirectly reflect the degree of cell damage. As shown in Fig. 1(A, B), the contents of MDA in the gills and digestive glands revealed significant increases at $2.5 \mu \mathrm{g} / \mathrm{g}$ CIP, further supporting the perception of an increase in ROS. MDA is produced from the decomposition of unsaturated fatty acid peroxides under the rapidly degraded by ROS (Yan et al., 2017). Thus, if the ROS content exceeded the elimination capacity of the antioxidant enzymes, the excess ROS could stimulate MDA production. Similar results have been reported in many studies (Legeay et al., 2005; Chen et al., 2014; Chen et al., 2015),MDA contents in the gills and digestive glands of $C$. fluminea were increased after exposure to organic pollutants and metals. 
Through the analysis of the above biomarkers, it can be concluded that sediment-associated CIP exposure significantly stimulated the antioxidant defense system of $C$. fluminea. The activities of SOD, GSH-Px, GR, and GST significantly increased in a dose dependent manner $(P<0.05)$ by the CIP treatments compared to the controls in all the four substrates to maintain the balance of oxidants and antioxidants, protecting cells from oxidative damage. However, the continuous CIP exposure increased the production of ROS, resulting in a significant decrease of CAT activity $(P<0.05)$. This may have caused the accumulation of $\mathrm{H}_{2} \mathrm{O}_{2}$. Meanwhile, the significant decrease of GST activity in the digestive gland indicated that the capacity of detoxification was decreased after continuous CIP exposure. The significant increases in MDA contents in both gills and digestive glands revealed clear cellular oxidative damage. These findings confirm that the balance of the antioxidant system was disrupted and was incapable of removing excess reactive oxygen species. Exposure to CIP eventually led to oxidative damage in the gills and digestive gland.

\subsection{Histological alterations of the digestive gland}

Cell morphological observation is the most basic approach in toxicological studies (Wu et al., 2019). Such observation can indicate the histopathological changes in an organism after exposure to xenobiotics. As a major organ for metabolism and bio-accumulation, the bivalves' digestive gland plays a significant role in the regulation and eradication of xenobiotics. The epithelial cells lining the tubules of the digestive gland are responsive to the negative effects of numerous contaminants (Vale et al., 2014). However, there are few reports of histological observations of freshwater bivalves under the effect of antibiotics. Therefore, the digestive gland of the freshwater bivalve $C$. fluminea was chosen to analyze cell morphology modifications following CIP exposure.

The normal structure of the digestive gland comprises a single layer of cells with a virtually occulted lumen (Vale et al., 2014; Cid et al., 2015). As shown in Fig. $2\left(a_{1}, a_{2}, a_{3}, a_{4}\right)$, the digestive gland tubules have an epithelium surrounded by a distinctive basal lamina and a well-defined Y-shaped lumen. After the exposure to CIP in different substrates, the microscopy observations revealed that almost no alterations of the digestive gland cells (Fig. $2 b_{1}, b_{2}, b_{3}, b_{4}$ ) were observed in the $0.01 \mu \mathrm{g} / \mathrm{g}$ exposure group. The clams exposed to concentrations higher than $0.01 \mu \mathrm{g} / \mathrm{g}$ were clearly affected, and enlargement of the tubule lumen and thinning of the epithelium in the digestive gland were observed. With the increase of exposure concentration, severe pathological changes in the digestive glands of $C$. fluminea were observed, including increase of vacuolation, the epithelial layer of the digestive gland becoming thinner, and irregular dilation of the lumen. The histopathological damage after exposure to $2.5 \mu \mathrm{g} / \mathrm{g}$ CIP was the most serious (Fig. $2 \mathrm{~d}_{1}, \mathrm{~d}_{2}, \mathrm{~d}_{3}, \mathrm{~d}_{4}$ ).

\subsection{Behavioral responses to the sediment-associated CIP}

Behavioral responses reveal the most direct impact of pollutants on organisms and have strong significance for biological monitoring (Zhou et al., 2008). Owing to the feeding behavior of $C$. fluminea mainly depending on the siphon, siphoning behavior has become an important indicator of general health or stress (Wu et al., 2019). The test results of siphoning behavior of $C$. fluminea are shown in Fig. 3 . The 
filtration rate was slightly inhibited in the low concentration $(0.01 \mu \mathrm{g} / \mathrm{g} \mathrm{CIP})$ treatment (Fig. 3). The adverse effects of CIP increased with increasing concentration (from $0.5 \mu \mathrm{g} / \mathrm{g}$ to $2.5 \mu \mathrm{g} / \mathrm{g}$ ). Previous studies have shown that many pollutants (such as bisphenol A, imidacloprid, and bifenthrin) result in reduced filtration rates by causing $C$. fluminea valves to close (Esperanza et al., 2020; Shan et al., 2020; Zhang et al., 2020). Valve closure regulation represents a trade-off between protection from the stressor and physiological performance (Esperanza et al., 2020). The reduction of filtration rate in this study may be related to cellular oxidative damage. With the increase in CIP concentration, the balance of the antioxidant system was disrupted and rendered incapable of removing excess reactive oxygen species. At the same time, $C$. fluminea protects the cells from oxidative damage by closing the valve and reducing its siphonage efficiency.

\subsection{Influence of different substrates on the toxic response of $C$. fluminea}

\subsubsection{Integrated biomarker responses in different substrates}

The Integrated Biomarker Response (IBR) approach is often used to identify impacts of environmental stresses on organisms (Sanchez et al., 2012; Beliaeff et al., 2002). To clarify toxicity differences of the CIP exposure groups with different substrates, IBR was applied to perform an integrated assessment of all of the biochemical parameters considered in this study. Seven parameters (i.e., SOD, CAT, MDA, GSH, $\mathrm{GSH}-\mathrm{Px}, \mathrm{GR}$, and GST) were chosen to obtain an integrated evaluation of the stress level of $C$. fluminea after exposure to CIP in four substrates. The results of IBR are presented as a radar chart in Fig. 4.

Figure 4 shows that IBR values increased in a concentration-dependent manner in all four substrate types after exposure to CIP. This indicates that the sediment-associated CIP did have an adverse health effect on $C$. fluminea, and the effect was gradually enhanced with the increase of exposure concentration. Meanwhile, different substrate compositions had certain effects on the biochemical parameters of the $C$. fluminea antioxidant defense system after the exposure to CIP (Fig. 4). For gill and digestive gland, the values of IBR at all of the exposure concentrations were significantly higher in the NOS group than in other substrate groups (Fig. 4). This may have been due to the fact that the bioavailability of the antibiotic in the NOS group was not affected by the sediment.

As shown in Fig. 4, the IBR values in the digestive gland in different substrate exposure groups were in the order of: NOS group > Sand group > SKC group > SCO group. The results also indicated that the bioavailability of CIP in the no-substrate group was the strongest, and the bioavailable antibiotic concentrations in the sand group, SKC group, and SCO group decreased gradually. Previous studies have shown that adsorption is the most important means of antibiotic transport in water and sediment (Tolls, 2001). The adsorption effect depends on the characteristics of the antibiotics and the sediment. The composition of the sediment has a large influence on the antibiotics adsorption, and the content of organic matter in the sediment is positively correlated with the adsorption capacity (Kaeseberg et al., 2018). In addition, smaller sediment particles with more adsorption sites have been regularly connected 
with greater pollutant adsorption (Crawford and Liber, 2015). The downward trend of IBR values was completely consistent with the adsorption characteristics of antibiotics in the four substrates. That is, with the rise of silt content, clay, and organic matter in the substrate composition, the concentration of antibiotics in the overlying water decreased gradually.

The IBR values in the gills in different substrate exposure groups were in the order of: NOS group > SCO group > SKC group > Sand group in all of the treatments $(0.01,0.5$, and $2.5 \mu \mathrm{g} / \mathrm{g})$. This may be due to the bioturbation effect of $C$. fluminea on the sediment that caused filtering and swallowing by the clam of organic matter, clay, and other fine sediment particles that adsorbed antibiotics. Filtration and swallowing of suspended particles and plankton are the principal energy supply pathways of this clam species $\mathrm{Wu}$ et al., 2019). Gills, as a gas exchange organ, are directly exposed to water contaminants. Compared to the digestive glands, organic matter, clay, and other fine particles adsorbing antibiotics in the sediment were more likely to have adverse effects on the gills. Therefore, the IBR values for the gills in the SCO group and SKC group were higher than in the Sand group.

\subsubsection{Cell morphology and Behavioral responses in different substrates}

Morphological alterations of cells are the result of profound changes at the physiological and biochemical levels (Zhang et al., 2020). As the IBR values shown in Fig. 4 indicate, the biochemical response of $C$. fluminea increased in a concentration-dependent manner in all four substrate types after exposure to CIP. Combined with the morphological damage shown in Fig. 2, these results revealed that the increased production of ROS after CIP exposure increased the oxidative damage to the organism, changed the expression of antioxidant enzymes, reduced the ability to scavenge free radicals, and caused severe tissue damage to the digestive glands of $C$. fluminea. There were differences in the changes of cell morphology between the NOS (water) group and sediment groups in the $2.5 \mu \mathrm{g} / \mathrm{g}$ CIP treatment (Fig. $2 \mathrm{~d}_{1^{-}}$ $d_{4}$ ). The thinnest epithelial cell layer with the most irregular changes and dilated lumina was observed in the NOS (water) group compared to the other three substrate groups. The trend of morphological structure changes of digestive gland cells in $C$. fluminea similar in the other three substrate groups. These results further suggest that the response of $C$. fluminea to toxins in the NOS group was the strongest.

The filtration rates were clearly influenced under the different substrate compositions by exposure to the high concentration of CIP ( 0.5 and $2.5 \mu \mathrm{g} / \mathrm{g}$, Fig. 3). The highest inhibition rate of siphoning behavior (filtration rate) was observed in the no substrate (NOS) group. The inhibitory degree of filtration rates in the higher concentration exposure groups $(0.5$ and $2.5 \mu \mathrm{g} / \mathrm{g})$ decreased in the order of Sand $>$ SKC $>$ SCO. This phenomenon may be attributed to the complete contact of $C$. fluminea with the pollutant in aqueous solution. Previous studies demonstrated $\mathrm{Cd}$ accumulation in $C$. fluminea to be highest when exposed in water and to decrease under exposure in sand and mud substrates (Graney et al., 1984). The results of our study may be well confirmed by this conclusion. Moreover, in the current study, the filtration rate of $C$. fluminea in the sand substrate group was least compared with the SKC and SCO substrate groups. Other researchers have found that in formulated sediments, compared to clay and organic matter, sand has the 
smallest adsorption amount for $U$ (Crawford and Liber, 2015). The minimal binding amount of the pollutant to the sand resulting in the content of pollutants in the overlying water will increase. Thus, $C$. fluminea in the sand group would absorb more pollutants through siphonage of the overlying water. This may well explain why the filtration rate of $C$. fluminea in the sand group was lower than in the other two groups.

\section{Conclusions}

The adverse influence of ambient concentrations CIP on $C$. flluminea under the influence of different substrate compositions was examined. The biochemical parameters response results revealed that the balance of the antioxidant system was disrupted, and oxidative damage appeared in the gills and digestive gland after sediment-associated CIP exposure. In terms of cell morphology and behavioral responses, CIP induced clear histopathological damage to the digestive gland and produced behavioral inhibition in the high concentration exposure groups. In addition, the substrate composition significantly influenced the activity of antioxidant enzymes and the siphoning behavior of $C$. fluminea after CIP exposure. Compared to the sediment group, the histopathological damage was greater in the no substrate (water) group. The current study has established a basis for future research on the toxic effects of CIP in $C$. fluminea in the sedimentary environment. The impacted pathways and genes expressed by $C$. fluminea after exposure to CIP need further exploration to characterize the toxicity mechanism.

\section{Declarations}

\section{Acknowledgment}

This work was supported by the Program for Guangdong Introducing Innovative and Enterpreneurial Teams (2019ZT08L213), the National Natural Science Foundation of China (42007368), and the National Key Research and Development Program of China (2016YFF0204502, 2016YFF0204500).

\section{Ethics approval and consent to participate}

Approval was obtained from the ethics committee of Guangdong University of Technology. The benthic bivalve- Corbicula fluminea used in this study was not listed as a protected species in China.

\section{Consent for publication}

Not applicable

\section{Availability of data and materials}

The datasets in this study are available from the corresponding author upon reasonable request. 


\section{Competing interests}

We declare that we do not have any commercial or associative interest that represents a conflict of interest in connection with the work submitted.

\section{Funding}

This work was supported by the Program for Guangdong Introducing Innovative and Enterpreneurial Teams (2019ZT08L213), the National Natural Science Foundation of China (42007368), and the National Key Research and Development Program of China (2016YFF0204502, 2016YFF0204500).

\section{Authors' contributions}

Xiaoyu Guo: Conceptualization, Methodology, Validation, Formal analysis, Investigation, Data curation, Writing - original draft. Chenghong Feng: Conceptualization, Methodology, Validation, Formal analysis, Investigation, Data curation, Writing - review \& editing, Supervision, Project administration, Funding acquisition. Zhe Bi: Review \& editing. Akhtar Islam: Review \& editing. Yanpeng Cai: Review \& editing

\section{References}

Arini, A., Daffe, G., Gonzalez, P., Feurtet-Mazel, A., Baudrimont, M. (2014) Detoxification and recovery capacities of Corbicula fluminea after an industrial metal contamination ( $\mathrm{Cd}$ and $\mathrm{Zn}$ ): A one-year depuration experiment. Environmental Pollution 192, 74-82

Beliaeff, B., Burgeot, T. (2002) Integrated biomarker response: A useful tool for ecological risk assessment. Environmental Toxicology \& Chemistry 21, 1316-1322

Boening, D. (1999)An Evaluation of Bivalves as Biomonitors of Heavy Metals Pollution in Marine Waters. Environmental Monitoring \& Assessment 55, 459-470

Carvalho, I.T., Santos, L. (2016) Antibiotics in the aquatic environments: A review of the European scenario. Environment International 94, 736-757

Coughlan, J. (1969) The estimation of filtering rate from the clearance of suspensions. Marine Biology 2, 356-358

Chen, H., Zha, J., Liang, X., Li, J., Wang, Z. (2014) Effects of the human antiepileptic drug carbamazepine on the behavior, biomarkers, and heat shock proteins in the Asian clam Corbicula fluminea. Aquatic Toxicology 155, 1-8

Chen, H., Zha, J., Yuan, L., Wang, Z. (2015) Effects of fluoxetine on behavior, antioxidant enzyme systems, and multixenobiotic resistance in the Asian clam Corbicula fluminea. Chemosphere 119, 856-862 
Chen, K., Zhou, J.L. (2014) Occurrence and behavior of antibiotics in water and sediments from the Huangpu River, Shanghai, China. Chemosphere 95, 604-612

Cid, A., Picado, A., Correia, J.B., Chaves, R., Silva, H., Caldeira, J., de Matos, A.P.A., Diniz, M.S. (2015) Oxidative stress and histological changes following exposure to diamond nanoparticles in the freshwater Asian clam Corbicula fluminea (Müller, 1774). Journal of Hazardous Materials 284, 27-34

Crawford, S.E., Liber, K. (2015) Effects of clay minerals and organic matter in formulated sediments on the bioavailability of sediment-associated uranium to the freshwater midge, Chironomus dilutus. Science of the total environment $532,821-830$

Csiszár, J., Horváth, E., Bela, K., Gallé, Á. (2016) Glutathione-Related Enzyme System: Glutathione Reductase (GR), Glutathione Transferases (GSTs) and Glutathione Peroxidases (GPXs). In: Gupta, D.K., Palma, J.M., Corpas, F.J. (Eds.). Redox State as a Central Regulator of Plant-Cell Stress Responses. Springer International Publishing, Cham, pp. 137-158

Doherty, F.G. (1990) The Asiatic clam, Corbicula spp., as a biological monitor in freshwater environments. Environmental Monitoring \& Assessment 15, 143

Esperanza, M., Seoane, M., Servia, M.J., Cid, Á. (2020) Effects of Bisphenol A on the microalga Chlamydomonas reinhardtii and the clam Corbicula fluminea. Ecotoxicology and Environmental Safety 197,110609

Feng, C., Guo, X., Yin, S., Tian, C., Li, Y., Shen, Z. (2017) Heavy metal partitioning of suspended particulate matter-water and sediment-water in the Yangtze Estuary. Chemosphere 185, 717-725

Feng, C., Zhao, S., Wang, D., Niu, J., Shen, Z. (2014) Sedimentary records of metal speciation in the Yangtze Estuary: Role of hydrological events. Chemosphere 107, 415-422

Fournier, E., Adam, C., Massabuau, J.C., Garnierlaplace, J. (2005) Bioaccumulation of waterborne selenium in the Asiatic clam Corbicula fluminea: influence of feeding-induced ventilatory activity and selenium species. Aquatic Toxicology 72, 251-260

Fu, L., Huang, T., Wang, S., Wang, X., Su, L., Li, C., Zhao, Y. (2017) Toxicity of 13 different antibiotics towards freshwater green algae Pseudokirchneriella subcapitata and their modes of action. Chemosphere $168,217-222$

Graney, R.L., Cherry, D.S., Cairns, J. (1984) The influence of substrate, pH, diet and temperature upon cadmium accumulation in the asiatic clam (Corbicula fluminea) in laboratory artificial streams. Water Research 18, 833-842

Guilhermino, L., Vieira, L.R., Ribeiro, D., Tavares, A.S., Cardoso, V., Alves, A., Almeida, J.M. (2018) Uptake and effects of the antimicrobial florfenicol, microplastics and their mixtures on freshwater exotic invasive bivalve Corbicula fluminea. Science of the total environment 622-623, 1131-1142 
Guo, X., Feng, C. (2018) Biological toxicity response of Asian Clam (Corbicula fluminea) to pollutants in surface water and sediment. Science of the total environment 631-632, 56-70

Herrero, A., Vila, J., Eljarrat, E., Ginebreda, A., Sabater, S., Batalla, R.J., Barceló, D. (2018) Transport of sediment borne contaminants in a Mediterranean river during a high flow event. Science of the total environment $633,1392-1402$

Ho, K.T., Burgess, R.M., Pelletier, M.C., Serbst, J.R., Ryba, S.A., Cantwell, M.G., Kuhn, A., Raczelowski, P. (2002) An overview of toxicant identification in sediments and dredged materials. Marine Pollution Bulletin 44, 286-293

Huang, Y., Wang, Y., Huang, Y., Zhang, L., Ye, F., Wang, J., Shang, J., Liao, Q. (2020) Impact of sediment characteristics on adsorption behavior of typical antibiotics in Lake Taihu, China. Science of the total environment 718,137329

Jiang, Y., Li, M., Guo, C., An, D., Xu, J., Zhang, Y., Xi, B. (2014) Distribution and ecological risk of antibiotics in a typical effluent-receiving river (Wangyang River) in north China. Chemosphere 112, 267-274

Jr. G. Allen Burton (2002) Sediment quality criteria in use around the world. Japanese Journal of Limnology 3, 65-76

Kaeseberg, T., Zhang, J., Schubert, S., Oertel, R., Siedel, H., Krebs, P. (2018) Sewer sediment-bound antibiotics as a potential environmental risk: Adsorption and desorption affinity of 14 antibiotics and one metabolite. Environmental pollution 239, 638-647

Legeay, A., Achard-Joris, M., Baudrimont, M., Massabuau, J., Bourdineaud, J. (2005) Impact of cadmium contamination and oxygenation levels on biochemical responses in the Asiatic clam Corbicula fluminea. Aquatic Toxicology 74, 242-253

Li, D., Wang, P., Wang, C., Fan, X., Hu, B. (2018) Combined toxicity of organophosphate flame retardants and cadmium to Corbicula fluminea in aquatic sediments. Environmental pollution 243, S597672460

Lubecki, L., Kowalewska, G. (2019) Plastic-derived contaminants in sediments from the coastal zone of the southern Baltic Sea. Marine Pollution Bulletin 146, 255-262

Luo, Y., Xu, L., Rysz, M., Wang, Y., Zhang, H., Alvarez, P.J.J. (2011) Occurrence and Transport of Tetracycline, Sulfonamide, Quinolone, and Macrolide Antibiotics in the Haihe River Basin, China. Environmental Science \& Technology 45, 1827-1833

Matić Bujagić, I., Grujić, S., Laušević, M., Hofmann, T., Micić, V. (2019) Emerging contaminants in sediment core from the Iron Gate I Reservoir on the Danube River. Science of the total environment 662, 77-87 
Ortmann, C. (2003) Energy metabolism and valve closure behaviour in the Asian clam Corbicula fluminea. Journal of Experimental Biology, 2003, 206(22):4167-4178

Qi, W., Müller, B., Pernet-Coudrier, B., Singer, H., Liu, H., Qu, J., Berg, M. (2014) Organic micropollutants in the Yangtze River: Seasonal occurrence and annual loads. Science of the total environment 472, 789-799

Ren, J., Luo, J., Ma, H., Wang, X., Ma, L.Q. (2013) Bioavailability and oxidative stress of cadmium to Corbicula fluminea. Environmental science. Processes \& impacts 15, 86-869

Riaz, L., Mahmood, T., Khalid, A., Rashid, A., Ahmed Siddique, M.B., Kamal, A., Coyne, M.S. (2018) Fluoroquinolones (FQs) in the environment: A review on their abundance, sorption and toxicity in soil. Chemosphere 191, 704-720

Roman, Y.E., De Schamphelaere, K.A.C., Nguyen, L.T.H., Janssen, C.R. (2007) Chronic toxicity of copper to five benthic invertebrates in laboratory-formulated sediment: Sensitivity comparison and preliminary risk assessment. Science of the total environment 387, 128-140

Rusina, T.P., Smedes, F., Brborić, M., Vrana, B. (2019) Investigating levels of organic contaminants in Danube River sediments in Serbia by multi-ratio equilibrium passive sampling. Science of the total environment 696,133935

Saidani, W., Sellami, B., Khazri, A., Mezni, A., Dellali, M., Joubert, O., Sheehan, D., Beyrem, H. (2019) Metal accumulation, biochemical and behavioral responses on the Mediterranean clams Ruditapes decussatus exposed to two photocatalyst nanocomposites (TiO2 NPs and AuTiO2NPs). Aquatic Toxicology 208, 7179

Sajjad. Zare, H.P. (2012) Changes activities of antioxidant enzymes in oilseed rape in response to salinity stress. International Journal of Agriculture and Crop Sciences 7, 398-403

Sanchez, W., Burgeot, T., Porcher, J.M. (2012) A novel "Integrated Biomarker Response" calculation based on reference deviation concept. Environmental Science \& Pollution Research 20, 2721-2725

Santos, K.C.D., Martinez, C.B.R. (2014) Genotoxic and biochemical effects of atrazine and Roundup ${ }^{\circledR}$; , alone and in combination, on the Asian clam Corbicula fluminea. Ecotoxicology and Environmental Safety $100,7-14$

Shan, Y., Yan, S., Hong, X., Zha, J., Qin, J. (2020) Effect of imidacloprid on the behavior, antioxidant system, multixenobiotic resistance, and histopathology of Asian freshwater clams (Corbicula fluminea). Aquatic Toxicology 218, 105333

Sheehan, D., Meade, G., Foley, V.M., Dowd, C.A. (2001) Structure, function and evolution of glutathione transferases: implications for classification of non-mammalian members of an ancient enzyme superfamily. The Biochemical journal 360, 1-16 
Silva, S.N., Azevedo, A.P., Teixeira, V., Pina, J.E., Rueff, J., Gaspar, J.F. (2009) The role of GSTA2 polymorphisms and haplotypes in breast cancer susceptibility: a case-control study in the Portuguese population. Oncology Reports 22, 593-598

Su, T., Shao, Q., Wang, P., Ma, C. (2016) Oxidative Stress and its Role in Peroxisome Homeostasis in Plants. In: Gupta, D.K., Palma, J.M., Corpas, F.J. (Eds.). Redox State as a Central Regulator of Plant-Cell Stress Responses. Springer International Publishing, Cham, pp. 117-136

Tolls, J. (2001) Sorption of Veterinary Pharmaceuticals in Soils: A Review. Environmental Science and Technology 35, 3397-3406

Trchounian, A., Petrosyan, M., Sahakyan, N. (2016) Plant Cell Redox Homeostasis and Reactive Oxygen Species. In: Gupta, D.K., Palma, J.M., Corpas, F.J. (Eds.). Redox State as a Central Regulator of Plant-Cell Stress Responses. Springer International Publishing, Cham, pp. 25-50

Vale, G., Franco, C., Diniz, M.S., Santos, M.M.C.D., Domingos, R.F. (2014) Bioavailability of cadmium and biochemical responses on the freshwater bivalve Corbicula fluminea-the role of TiO2 nanoparticles. Ecotoxicology and Environmental Safety 109, 161-168

Wang, D., Ning, Q., Dong, J., Brooks, B.W., You, J. (2020) Predicting mixture toxicity and antibiotic resistance of fluoroquinolones and their photodegradation products in Escherichia coli. Environmental pollution 262,114275

Wang, Q., Hong, X., Chen, H., Yuan, L., Zha, J. (2018) The neuropeptides of Asian freshwater clam (Corbicula fluminea) as new molecular biomarker basing on the responses of organophosphate chemicals exposure. Ecotoxicology and Environmental Safety 160, 52-59

Wu, Y., Gu, E., Li, H., Tian, C., Feng, C. (2019) Oxidative stress and histological changes in Corbicula fluminea exposed to nano-Al13 and monomeric Al coagulants. Environmental Science: Nano 6, 27362748

Xu, J., Zhang, Y., Zhou, C., Guo, C., Wang, D., Du, P., Luo, Y., Wan, J., Meng, W. (2014) Distribution, sources and composition of antibiotics in sediment, overlying water and pore water from Taihu Lake, China. Science of the total environment 497-498, 267-273

Yan, S., Wu, H., Qin, J., Zha, J., Wang, Z. (2017) Halogen-free organophosphorus flame retardants caused oxidative stress and multixenobiotic resistance in Asian freshwater clams (Corbicula fluminea). Environmental pollution 225, 559-568

Yang, J.F., Ying, G.G., Zhao, J.L., Tao, R., Su, H.C., Chen, F. (2010) Simultaneous determination of four classes of antibiotics in sediments of the Pearl Rivers using RRLC-MS/MS. Science of the total environment 408, 3424-3432 
Zhang, H., Hong, X., Yan, S., Zha, J., Qin, J. (2020) Environmentally relevant concentrations of bifenthrin induce changes in behaviour, biomarkers, histological characteristics, and the transcriptome in Corbicula fluminea. Science of the total environment 728,138821

Zhou, Q., Zhang, J., Fu, J., Shi, J., Jiang, G. (2008) Biomonitoring: An appealing tool for assessment of metal pollution in the aquatic ecosystem. Analytica Chimica Acta 606, 135-150

\section{Figures}

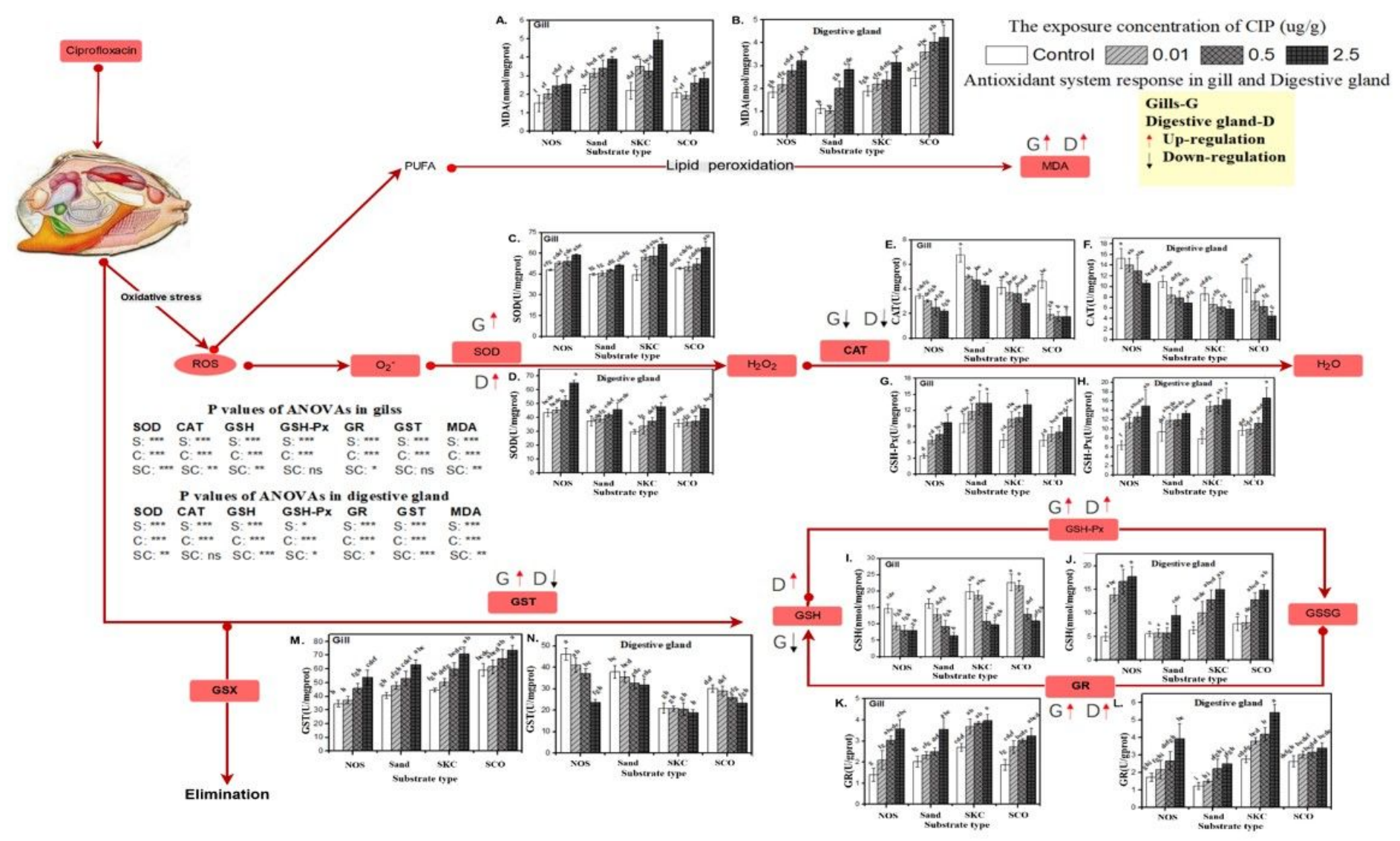

Figure 1

Association of enzymatic and non-enzymatic antioxidants in the antioxidant defense system of Corbicula fluminea and the effects of ciprofloxacin on the biochemical parameters of antioxidant defense system in gill $(A, C, E, G, I, K, M)$ and digestive gland $(B, D, F, H, J, L, N)$ under different substrates. Bars indicate the mean $\pm S D(n=3)$; P values of ANOVAs of CIP concentrations $(C)$, substrates influence $(S)$, and their interactions (SC) were also shown. ( ${ }^{*}<<0.05 ;{ }^{* \star P}<0.01$; ${ }^{\star * *} \mathrm{P}<0.001$; ns: not significant). A,B-MDA C,D -SOD E,F-CAT G,H-GSH-Px I,J-GSH K,L-GR M,N-GST; NOS: no substrate (Water); Sand (100\%); SKC: sand $(75 \%)$, kaolinite clay (25\%); SCO: sand (75\%), kaolinite clay (20\%), and organic matter (5\%): PUFA, polyunsaturated fatty acid; GSX, glutathione-S-conjugate; GSSG, oxidized glutathione. 


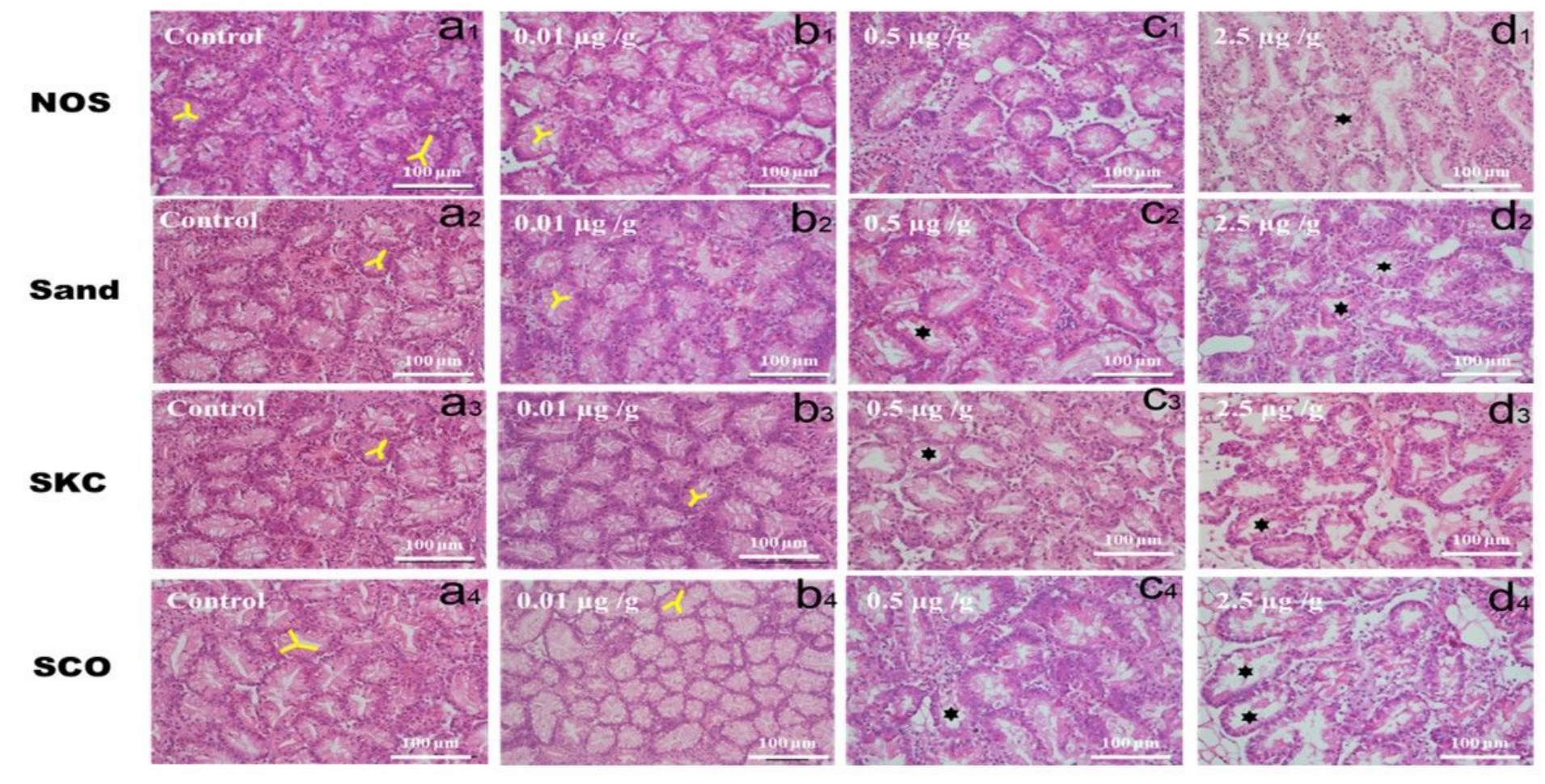

Figure 2

Morphology of digestive gland cells of Corbicula fluminea after 10 days of ciprofloxacin exposure in four

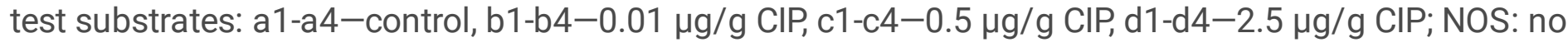
substrate (Water); Sand (100\%); SKC: sand (75\%), kaolinite clay (25\%); SCO: sand (75\%), kaolinite clay $(20 \%)$, and organic matter (5\%). 


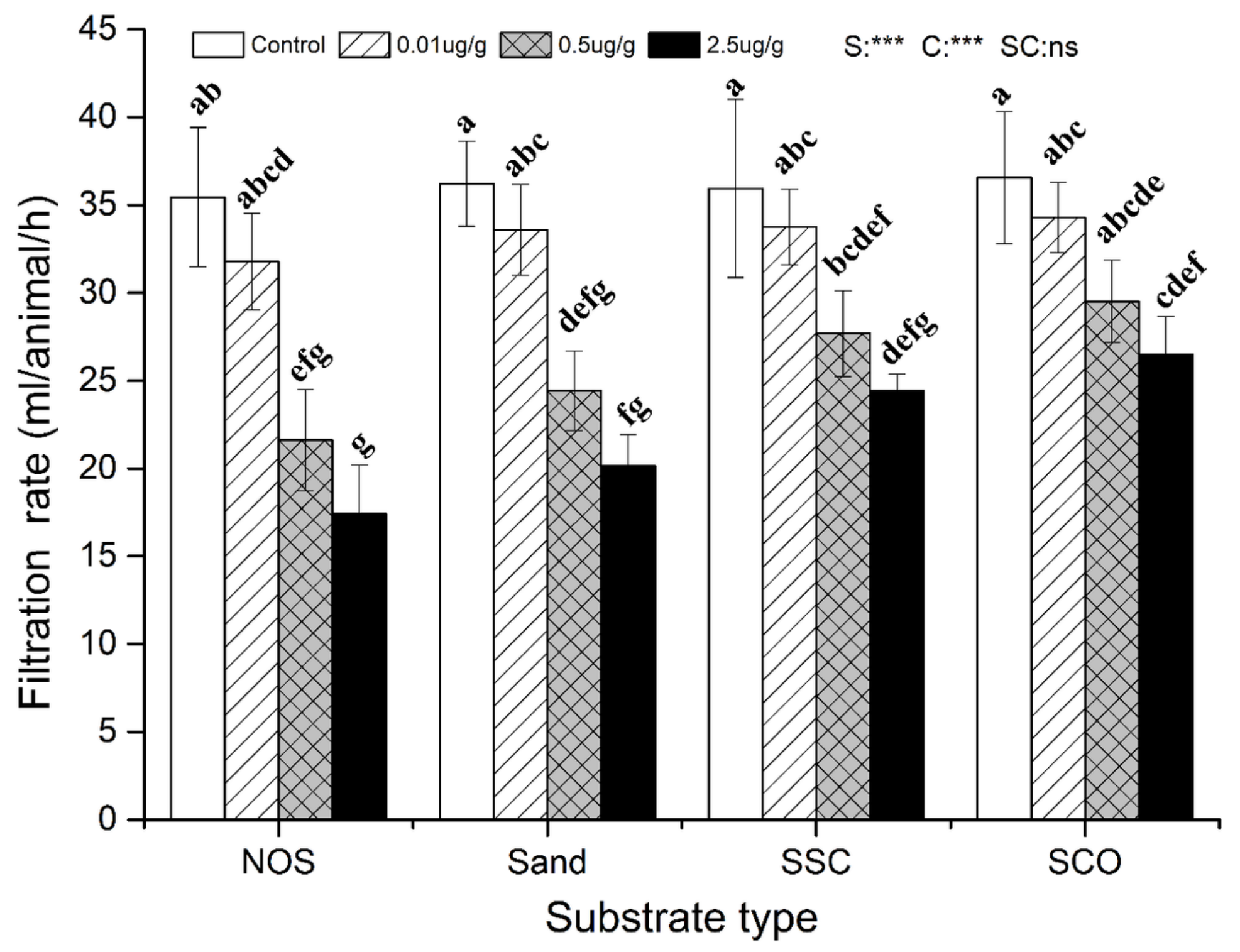

Figure 3

Effects of ciprofloxacin on the filtration rate of Corbicula fluminea under different substrates (NOS: no substrate (Water); Sand (100\%); SKC: sand (75\%), kaolinite clay (25\%); SCO: sand (75\%), kaolinite clay $(20 \%)$, and organic matter $(5 \%))$. Bars indicate the mean \pm SD $(n=3)$; P values of ANOVAs of CIP concentrations (C), substrates influence $(S)$, and their interactions $(S C)$ were also shown. $\left({ }^{\star * \star} P<0.001\right.$; ns: not significant). 


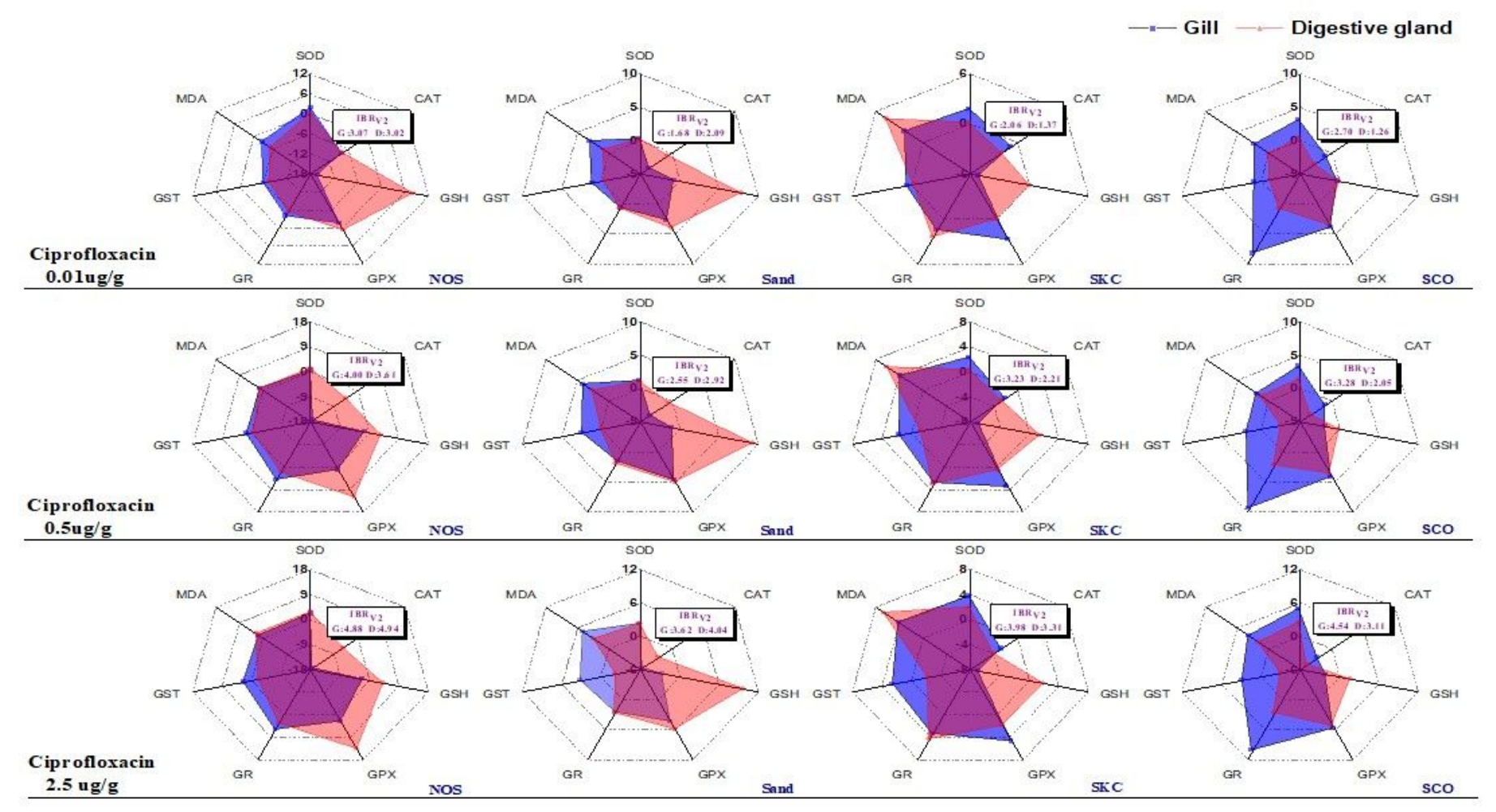

\section{Figure 4}

Integrated biomarker response index version 2 (IBRv2) radar map of organ biomarkers of Corbicula fluminea under exposure to ciprofloxacin in different substrates (the area above 0 reflects induction of the biomarker, and below 0 indicates reduction of the biomarker. G: Gill, D: Digestive gland)

\section{Supplementary Files}

This is a list of supplementary files associated with this preprint. Click to download.

- Supplementaryinformation.docx 